\title{
Antibiofilm Activity of Natural Products: Promising Strategies for Combating Microbial Biofilms
}

\author{
Nagela Bernadelli Sousa Silva ${ }^{1^{*}}$, Lara de Andrade Marques ${ }^{2}$ and Denise von Dolinger de \\ Brito Röder ${ }^{3}$
}

\author{
${ }^{1}$ Post Graduate Student in Applied Immunology and Parasitology, Institute of Biomedical Sciences, Federal \\ University of Uberlândia, Uberlândia, Minas Gerais, Brazil \\ ${ }^{2}$ Post Graduate Student in Health Sciences, Medical School, Federal University of Uberlândia, Uberlândia, \\ Minas Gerais, Brazil
}

${ }^{3} \mathrm{PhD}$ in Clinical Microbiology, Professor of Institute of Biomedical Sciences, Federal University of Uberlândia, Uberlândia, Minas Gerais, Brazil

\begin{abstract}
Microbial biofilm is defined as an association of bacterial and fungal cells, fixed to surfaces, biotic or abiotic, included in a complex extracellular matrix of polymeric substances (EPS). It is estimated that approximately $65 \%$ of microbial infections are caused by biofilm-forming microorganisms, representing a serious public health problem. In addition, the integrity of machinery and equipment in industries can be compromised by the presence of biofilms, causing significant economic losses. Therefore, there is an urgent need to discover new drugs that are effective against biofilms, which are nontoxic. Natural products have been extensively studied due to their enormous antimicrobial efficacy, like garlic, chitosan derivatives, various peptide spices, products derived from plants and essential oils. Thus, the purpose of this review is to describe the most promising anti-biofilm compounds derived from natural products for bacteria and fungi. One way of treating infections is to use medicinal plants. They have several compounds that have antimicrobial properties and raise your interest in medicine for the treatment of infections. Essential oils are secondary metabolites produced by plants; they act by damaging the extracellular matrix and eliminate adherence factors, contributing to the failure in the construction of the biofilm. Other strategy is the Cationic antimicrobial peptides (AMPs). They are short linear amino acid sequences, which display antimicrobial activity against a wide range of bacterial species. It is a promising novel antimicrobials since they have shown bactericidal effects against multiresistant bacteria. Bacteria and fundi are also capable of producing substances such as peptides and other compounds, which can act as antimicrobials, inhibiting the growth of other microorganisms. This review describes the most promising anti-biofilm compounds, derived from natural products that act against bacteria and fungi. However, the treatment with these compounds must bestudied in detail, since biofilms increase microbial resistance and have strategies to decrease the penetration of antimicrobial substances through their polysaccharide matrix.
\end{abstract}

\section{Introduction}

Microbial biofilm is defined as an association of bacterial and fungal cells, fixed to surfaces, biotic or abiotic, included in a complex extracellular matrix of polymeric substances (EPS) [1]. EPS has a varied chemical composition, and not only provides the organic structure of the biofilm, but also facilitates the spatial arrangement of the different species that compose it. The main components of EPS are polysaccharides, proteins, nucleic acids, glycoprotein's and phospholipids. This extracellular matrix is formed partly by the cells themselves and partly by components of the environment, such as debris, proteins, inorganic materials and even other living things [2]. The composition and quantity of components of the extracellular matrix is different in fungi and bacteria. Each species and lineage of microorganism has a type of extracellular matrix, which also depends on the environmental niche where the biofilm was formed [3]. This matrix strongly adheres to biotic and abiotic surfaces, causing persistent and difficult-to-treat infections [1].

*Corresponding author: Nagela Bernadelli Sousa Silva, Post Graduate Student in Applied Immunology and Parasitology, Institute of Biomedical Sciences, Federal University of Uberlândia, Av. Amazonas, S/N - Umuarama, Uberlândia, Minas Gerais, Brazil

Accepted: November 10, 2020

Published online: November 12, 2020

Citation: Silva NBS, Marques LA, Röder DDB (2020) Antibiofilm Activity of Natural Products: Promising Strategies for Combating Microbial Biofilms. Ann Public Health Reports 4(1):92-99 
In addition, the EPS hinders the passage of antibiotics and other injurious substances to the bacterial community, increasing microbial resistance [4]. Bacteria and fungi in biofilms are more resistant to antimicrobials than free-living microorganisms, with minimum eradication concentrations of 10 to 1,000 times higher compared to planktonic bacteria. The most antibiotics commonly used in medical practice are effective only for planktonic bacteria [5] and there are still no standardized and reliable protocols for their administration for this purpose.

The formation of biofilm can be divided into four stages: I) Initial adhesion of planktonic cells to surfaces; II) Irreversible adhesion and formation of micro colonies; III) Maturation of biofilm and IV) release of persister cells [6]. In the first and second stages planktonic bacteria called primary colonizers adhere to a surface, forming a conditioning film, which will allow initial adhesion. Subsequently, the production of EPS begins to form the polymeric extracellular matrix, resulting in the irreversible adhesion of microorganisms to the contact surface. In this phase, microorganisms already adhered to the surface, start cell multiplication and the extracellular polysaccharide acts as a kind of glue, to group microbial cells. The third stage is characterized by intense cell multiplication and the formation of water channels allowing the entry of proteins, oxygen and substrates. In this phase, the biofilm is in its mature phase, with all its architecture assembled. In the last stage, specific microbial cells called persisters are released from the biofilm, in order to adhere to other surfaces, forming a new biofilm elsewhere $[7,8]$.

The biofilm allows the microorganism to survive even in hostile environments, until it can multiply in a more favorable environment. It is estimated that approximately $65 \%$ of microbial infections are caused by biofilm-forming microorganisms, representing a serious public health problem due to the evasion of the host immune system and the resistance of most antimicrobials used for treatment, increasing the persistence of the infection [9]. Additionally, biofilms contribute to the increase in morbidity and mortality rates and hospital costs, making it difficult to treat and eradicate infections [8]. In addition, the integrity of machinery and equipment in industries can be compromised by the presence of biofilms, causing significant economic losses $[10,11]$. Therefore, there is an urgent need to discover new drugs that are effective against biofilms, which are non-toxic [12].

Natural products have been extensively studied due to their enormous antimicrobial efficacy, difficulty to gain resistance against them and their safety to use in different fields and industries [13]. Garlic, chitosan derivatives, various peptide spices, products derived from plants and essential oils, are examples of these products, which can act to combat biofilms in different ways, as preventing bacterial adhesion to surfaces; interfering in the production of chemical molecules crucial for their development and disrupting the extracellular matrix [14-16].

Thus, the purpose of this review is to describe the most promising anti-biofilm compounds derived from natural products for bacteria and fungi.

\section{Anti-Biofilm Activity of Natural Products: Bacterial Biofilm Control Strategy}

\section{Medicinal plants}

One way of treating infections is to use medicinal plants. They have several compounds that have antimicrobial properties and raise your interest in medicine for the treatment of infections. Plants are rich in a wide variety of secondary (phytochemical) metabolites, such as polyphenols, flavonoids, terpenoids, alkaloids and tannins [17], which have been shown to have antimicrobial properties [17-20].

Some examples are licorice root, purple coneflower flower and stem, sage leaves and ethanol extracts from the inner elm bark. They were effective against biofilms of Streptococcus pyogenes in pharyngitis, as there was an impact on the cell wall and the degradation of the bacterial membrane, which reduces planktonic growth, decreasing the population to form the biofilm [17]. Licorice root and sage extracts showed bacteriostatic effect in the first 2 hours of exposure; from that moment on, they established a progressive decrease in the bacterial cell count and showed a bactericidal effect after 3 hours. The purple cone flora flower extract provided a bacteriostatic effect in the first 4 hours of exposure, after which it established its bactericidal effect.

Another compound is garlic extract (Allium sativum), which was effective in penetrating and stopping well-established (MRSA) Methicillin-Resistant Staphylococcus aureus biofilms and is a promising alternative for the treatment of chronic infections related to the formation of biofilms by bacteria resistant to medications [14]. Another example is Ursolic Acid (UA) and Oleanolic Acid (OA), triterpenoid compounds isolated from many edible and medicinal plants and combated biofilms from cariogenic microorganisms, with UA having greater antibacterial activity than OA. Both showed greater antibacterial activity against Actinomyces spp. than Streptococcus spp. UA and OA in 1/4 MIC can reduce the formation of bacterial biofilm, while higher concentrations of UA exhibited antibacterial activity against Actinomyces viscosus and Streptococcus mutans in mature biofilms [21].

\section{Essencial oils}

Essential oils are secondary metabolites produced by plants. A study conducted by Kavanaugh and Ribbeck [22], demonstrated that red thyme, cassia, tea tree and clove oils were effective against the biofilm formed by strains of MRSA. They act by damaging the extracellular matrix of $S$. aureus and eliminate adherence factors, contributing to the failure in the construction of the biofilm.

The effectiveness in inhibiting biofilm formation can occur with treatment based on the combination of several essential oils through a synergistic effect and preventing the emergence of antimicrobial resistant microorganisms [23].

A study by Husain, et al. [24] showed that Mentha piperita oil in sub-minimum inhibitory concentrations regulated virulence factors and biofilm formation in Pseudomonas aeruginosa and Aeromonas hydrophila. The essential oil menthol 
has also been tested and reduced the production of virulence factors and biofilm formation, being identified as a new broad-spectrum quorum sensing inhibitor against Gram-negative bacteria. In a study by Wijesundara and Rupasinghe [17], essential oils extracted from oregano, sage, cloves and ginger were evaluated for phytochemical profile, antibacterial and anti-biofilm activities against Streptococcus pyogenes. The essential oils of oregano and sage exhibited bactericidal effects in 5 minutes and 4 hours, respectively, acting as a potent anti-biofilm agent with double action, preventing and eradicating the biofilm. They concluded that the essential oils of oregano and sage inhibit the growth and biofilm formation of $S$. pyogenes and can be used in the development of potential plant-derived antimicrobial agents in the treatment of Streptococcal pharyngitis.

\section{Peptides}

Cationic antimicrobial peptides (AMPs) are short linear amino acid sequences, which display antimicrobial activity against a wide range of bacterial species. They are promising novel antimicrobials since they have shown bactericidal effects against multiresistant bacteria. Their amphiphilic structure with hydrophobic and cationic regions drives their interaction with anionic bacterial cytoplasmic membranes, which leads to their disruption. It is positively charged amphipathic oligopeptides and consists of five to one hundred amino acids [25]. An example is human catelicidin LL-37, which can form an alpha helix when in contact with bacterial membranes and inhibit the ability of bacteria to form and biofilm without affecting the growth of S. epidermidis ATCC 35984 [26]. The helical catelicidin identified in the Chinese snake (Najaatra) has anti-biofilm activities against $S$. aureus [27]. These peptides may be useful for the treatment of chronic wounds, since they also demonstrate low cytotoxicity against host cells [23].

A study by Gordya and collaborator [28] showed that antimicrobial peptides exhibited strong matrix destruction activity of Escherichia coli biofilms, S. aureus and antimicrobial resistant Acinetobacter baumannii, as well as non-toxicity to human immune cells. Martínez, et al. [29] showed that the peptide $\mathrm{P} 5$ showed antibiofilm activity in strains of $P$. aeruginosa and S. aureus, while P6.2 only in S. aureus. Both peptides were analyzed in vivo, in the lungs of neutropenic mice previously instilled with $P$. aeruginosa. The lungs of mice were surgically extracted and pro-inflammatory bacteria and cytokines (IL- $\beta$, IL- 6 and TNF- $\alpha$ ) were quantified by colony forming units and ELISA, respectively. The results showed that the instillation of the peptides produced a significant decrease in the number of live bacteria in the lungs, concomitant with a decrease in the pro-inflammatory cytokines, showing that in general, the results presented suggest that these two new peptides may be good candidates for the future development of drugs for anti-biofilm and anti-infective therapy.

\section{Bactericidal compounds derived from microor- ganisms}

Bacteria are capable of producing substances such as peptides and other compounds, which can act as antimicrobials, inhibiting the growth of other microorganisms. Streptomyces is the largest genus of Actinobacteria and the type genus of the family Streptomycetaceae. These bacteria were selected in the study by Saleem and collaborators [30] to evaluate anti-biofilm effects of dental plaque bacteria, including Acinetobacter schinndleri and Moraxella aci. The results showed that the extracts of Streptomyces erythrogriseus and Streptomyces labedae exhibited anti-biofilm activity against Acinetobacter schinndleri and Moraxella aci. Another example is Actinobacteria spp. that inhibited the formation of $S$. aureus biofilm by more than $80 \%$ without affecting growth [16].

\section{Weak acids: the power of acetic acid and citric acid in controlling biofilms}

A combination of factors is likely to lead to a bacteriostatic and bactericidal effect of Weak Acids (WA). One of these factors is that they are relatively hydrophobic, can spread through bacterial cell membranes, dissociate and reduce the bacterium's internal cytoplasmic $\mathrm{pH}$, leading to a disruption of metabolic activities and the consequent intracellular accumulation of WA degradation products. An example of WA is acetic acid. It is used to treat infections caused by Pseudomonas aeruginosa in burns [31] and chronic pressure injuries [32], being applied topically in dressings in concentrations between 2 and 5\%. Another example is the citric acid used in hematology and oncology in the technique of antibiotic blocking in vascular catheter infections, with concentrations of $5 \%$ [33].

\section{Anti-Biofilm Activity of Natural Products: Strategy for the Control of Fungal Biofilms}

\section{Medicinal plants}

There are several studies involving plant extract in the fight against oral biofilm, such as Stanciuc and collaborators [34], in whichdescribed the antimicrobial activity of Arnica montana, Artemisia absinthium and Urtica dioica plants against biofilms formed by Staphylococcus aureus and Candida albicans in the oral cavity. Choi and collaborators [35] also demonstrated the power of inhibition in more than $90 \%$ of biofilm formation by dental pathogens Streptococcus mutans and Candida albicans using the extract of Camellia japonica and Thuja orientalis.

Freitas, et al. [36] also identified the antimicrobial potential against the biofilm formed by Candida sp. of the leaf extract of a fruit tree called Persea americana. According to this study, the leaves of this tree are composed of flavonoids and other phenolic compounds that are able to form complexes with soluble proteins present in the Candida cell and break its membrane, as it has a high penetrating power. In addition, they contribute to the enzymatic inactivation of microorganisms in the biofilm, as an inhibition of protein synthesis and important structures of this community such as the extracellular matrix. Other phenolic compounds, such as tannins and quinones isolated from other plants, have also been described acting in the inhibition of bacterial adhesion, as well as in mature biofilm and dispersion in strains of $C$. albicans, $C$. dublinienses and C. tropicalis [37].

Berberine is another natural alkaloid compound isolat- 
ed from roots, stems and rhizomes of natural herbs such as Berberis aquifolium, Berberis vulgaris, Berberis aristata, Hydrastis canadensis and Phellodendron amurense, which has antifungal properties, as demonstrated by Silva and and colleagues [38]. In its study, the antifungal potential of berberine against planktonic strains of $C$. tropicalis and Cryptococcus neoformans resistant to fluconazole and against the biofilm formed by strains of $C$. tropicalis was evaluated. Cytometric analysis showed that the treatment with this compound led to the cell death of these microorganisms, for causing damage to DNA and plasma integrity. Against biofilm,treatment with this compound demonstrated a significant reduction in cell viability and cell activity in the biofilm.

Cochlospermum regium, also known as yellow cotton, is also a tree that has been studied, due to its root extract showing antimicrobial action against several microorganisms such as Staphylococcus aureus, Pseudomonas aeruginosa and C. in tropicalis. Recently, Almeida-Apolonio, et al. [39], also discovered an antibiofilm activity of the extract of this tree, against biofilms formed by Cryptococcus gattii, demonstrating a reduction in the biomass of the mature biofilm after treatment with the extract, decreasing by up to $42.58 \%$ the number of viable cells compared to the control.

\section{Essencial oils}

Essential oils are other excellent candidates for new antimicrobial agents, as their isolated compounds, including terpenes and terpenoids and aromatic compounds, have been demonstrating antimicrobial activity against a wide range of microorganisms. They are lipophilic compounds, so they pass through the cell wall and the plasma membrane, disrupting the network of peptideoglycans, making the membrane permeable [40].

Thymus vulgaris essential oil is widely used for the treatment of depression and tiredness, but its active constituent thymol, being studied due to its antimicrobial, antioxidant and anti-inflammatory potential. Jafri and Ahmad, [15] described the potential antibiofilm of $T$. vulgaris and thymol in strains of $C$. albicans and $C$. tropicalis.

The essential oils Cinnamomum tamala and Cinnamomum camphora extracted from plants Pogostemon spp. and Cinnamomum spp plants, have also antibiofilm action in strains of Candida sp, as demonstrated by Banu, et al. [41]. These oils are capable of breaking the structure of the mature biofilm with an inhibition percentage of around $55-67 \%$, and can also act in the early stages of the biofilm, decreasing the cell viability of the biofilm.

The action of essential oils can act in synergism with other main compounds, such as eugenol, thymol and carvacrol, active compounds in the thyme oil, which act by inhibiting the efflux pump activity, as well as the essential oil Menthol suaveolens, which through the compounds of linalool and borneol acts to restrict biofilm in strains of Candida sp. In addition, linalool and $\alpha$-pinene from thyme oil demonstrated antifungal activity against the yeast Pichia anomala and anti-quorum sensing effect by inhibiting the expression of $\mathrm{N}$-acylhomoserine lactone (ALH) in Chromobacterium violaceum. Other stud- ies have already described the antifungal action of essential oils, such as eucalyptus, peppermint, ginger and clove oils, which reduced biofilm formation by approximately $80 \%$, altering the cell viability of the microbial community [42].

Anothter type of oil essencial is from Piper sp. This tree belongs to the family Piperacea, widely distributed worldwide. They are used in folk medicine to treat diseases, as they provide therapeutic essential oils. It has been studied for the treatment of zygomycosis, also known as phycomycosis or mucormycosis, a severe and aggressive infection that occurs in immunocompromised patients. Among all its active compounds, Piper sp. demonstrated to be the most active agent against planktonic and sessile forms of the Rhizopus oryzae microfungus. In addition, this oil showed antifungal action against Cladosporium cladosporioides and C. sphareospermum [43].

\section{Peptides}

There are peptides isolated from plants, such as Psd1 isolated from seeds of Pisum sativum, which has been shown to be a promising antibiofilm compound for strains of $C$. albicans. This peptide works by disaggregating the extracellular matrix, increasing stiffness and roughness and interfering with the cell cycle of fungal cells, leading to apoptosis. Catelicidins are peptides isolated from different species of mammals and exhibit antifungal and antibiofilm activity in a wide range of fungi. The peptides LL-37 and BMAP-28 are examples of catelicidins, which act in the inhibition of biofilm formation and in the removal of mature biofilm, respectively, from strains of Candida sp. isolated from medical devices and urinary infections. Histatins are a group of proteins isolated from human saliva, being divided into histatin 1 to 5 . Histatin 5 is able to reduce the metabolic activity of biofilms formed by $C$. albicans and $C$. glabrata. Studies report that histatins are antifungal agents that act selectively with low toxicity to mammals, being considered a promising antibiofilm compound, especially for oral fungal biofilms [44].

Some peptides isolated from fruits have also been studied due to their antibiofilm action, such as the fruits of the tree Trapa natans, an aquatic plant that was able to inhibit $50 \%$ the biofilm formed by $C$. tropicalis. Another example of antifungal peptides is the decapeptides isolated from the Arabidopsis thaliana plant, capable of inhibiting the biofilm of C. albicans without any toxicity in various human cells such as osteoblasts, stem cells and endothelial cells. The glycopetid-rich hydroxupoline extracted from the pericarp of the Datura stramonium plant also has an action against the biofilm formed by $C$. albicans, with a minimum concentration of eradication of the biofilm of $2 \mu \mathrm{M}$ [37].

\section{Fungicidal compounds derived from microor- ganisms}

Saccharomyces cerevisiae is a yeast that is capable of producing several types of macrotetrolides (nonactin, monactin, dinactin and trinactin), which has antifungal action against $C$. albicans, Cryptococcussp., C. kruzei and C. albicans resistant to fluconazole. Regarding biofilm, according to Tebbets, et al. [45], the monactin, dinactin and trinactin produced by S. cere- 
visiae demonstrated antibiofilm action in vitro against strains of C. albicans. Dinactin also showed antibiofilm action in vivo in an infection model in rats using a catheter.

The bacterium Bacillus subilitis is also capable of producing antifungal compounds, as demonstrated by Ceresa and collaborators [46]. The mixture of the lipopeptide with other compounds produced by this pbactperia, such as surfactin, was able to inhibit the adhesion of the $C$. albicans biofilm.

Another example is the yeast Trichosporon montevideense that produces a polymer capable of inhibiting biofilm formation by C. albicans and C. krusei [47].

\section{Clinical Relevance of Biofilms and Treatment Strategies Using Natural Products}

The number of biofilm-related infections in hospital settings is significant. In developed countries, approximately $80 \%$ of patients with cystic fibrosis develop chronic infection of the lungs and paranasal sinuses. In patients with chronic wounds, more than $60 \%$ will develop biofilms. Of the patients who have orthopedic devices, $0.5 \%$ to $2 \%$ develop an infection within two years of the surgical procedure. Additionally, of the patients admitted to the ITU-Intensive Care Unit, unsing intravenous catheters, 5 of 1000 develop bloodstream infection related to the use of catheters, most of them caused by microorganisms that produce biofilms. In addition, about 50\% of the implanted urinary catheters become colonized in the first 10-14 days after insertion [48].

One of the biofilm strategies for persisting infections is to resist the flow of fluids or other mechanical forces that work to wash or sweep microorganisms out of the body. As an example in dental plaque, a spectrum of forces is exerted on the oral biofilm. The biofilm will only accumulate if it is strong enough to resist rupture by frequent forces or is able to regress in the intervals between intense, but infrequent forces. Brushing is effective precisely because it is powerful enough to remove much of the biofilm [45].

Biofilms are able to adhere to various surfaces, making it stable and viable for longer due to matrix production. In natural environments, microbial cells need to adapt to changes in the environment, whereas cells belonging to the biofilm do not need this adaptation, as the matrix provides the exchange of oxygen and organic nutrients, in addition to protecting the entire community from any change in the environment. external environment. The formation of biofilm allows the microorganism to survive even in hostile environments, until it can multiply in a more favorable environment. In ITU, it is known that the risk of transmission is directly proportional to the survival time of the bacteria in the unit. Depending on the environmental, geographic conditions and the ability of the bacteria to form biofilm, these pathogens can remain on neonatal surfaces for months [49-50].

Potentially, biofilms will only form in wet or damp areas, however thepresence of nutrients also favors this phenomenon. Cleaning procedures must ensure the effective removal of food scraps and other residues that may provide nutrients and or contain microorganisms, encouraging their multipli- cation [51]. These biofilm-producing and multidrug-resistant pathogens represent a public health and problem, especially in underdeveloped countries like Brazil, where hospital units are overcrowded and lack of human and financial resources [52].

In addition, the mature biofilm releases cells from within the biofilm to the external environment (persistent cells) in order to form new microbial communities in other sites. These persistent cells are tolerant of most antimicrobials and cleaning substances, being more virulent than the bacteria themselves that were in their original biofilm. The time it takes for a biofilm to reach its mature stage and start releasing these cells varies from each microorganism, but most bacteria take around 24 hours and after being released, in a matter of hours the persistent cells can adhere irreversibly to surfaces. The contribution of persistent cells to the pathogenesis of infection has been much discussed in recent years, but it is already known that bacteria deficient in the production of type IV pili required for cell dispersion, are 200 times less virulent than producing bacteria. These cells contribute to the recurrence of the infection and its persistence in the patient, contributingto increase the morbidity and mortality of hospital units [53].

Therefore, the treatment of biofilms, especially in the clinical area, becomes extremely important. To date, there is still no method for detecting biofilm production in the clinic, as well as fully effective and safe therapies for the treatment of infections associated with this virulence factor. The production of biofilm remains a challenge in the health area, representing a risk mainly for inpatients in which they are at risk [54]. Recently, some research has attempted to seek antibiofilm strategies through plant extracts and molecules produced by the bacteria themselves in mixed antagonistic biofilms, in an attempt to inhibit the early stages of biofilm, as well as Quorum-sensing.

The main treatments for biofilm based on natural products are described in Table 1. Escherichia coli uropathogenic, contains many virulence factors that allow bacteria to add various mechanisms of resistance to the immune system and antibiotics, such as the formation of biofilm. Essential oils have been studied for their anti-biofilm effect, such as Rosmarinus officinalis [55]. Other studies have also reported the action of Betula pendula inhibited the formation of biofilm by uropathogenic $E$. coli up to 50\% [53]. Medicinal plants have also been studied, due to their therapeutic potential against the formation of biofilms. Scutellaria spp. is a botanical genus of the Lamiaceae family, often found in temperate regions and tropical mountains. Chen and colleagues [56] described in their study, the antibacterial action of the Baicalein component of this plant against biofilms formed by MRSA, inhibiting RNAlll transcription. MRSA pathogens are primarily responsible for infections in soft tissues and mucous membranes, which can lead to death.

With regard to oral infection, the Porphyromonas gingivalis bacterium is an anaerobic bacterium pointed out as one of the main responsible for the formation of biofilm in the oral cavity, which can cause periodontal diseases. Curcumin is a 
Citation: Silva NBS, Marques LA, Röder DDB (2020) Antibiofilm Activity of Natural Products: Promising Strategies for Combating Microbial Biofilms. Ann Public Health Reports 4(1):92-99

Table 1: Main natural products with antibiofilm action against bacteria and fungi of clinical relevance.

\begin{tabular}{|c|c|c|c|}
\hline Treatment & Site & Microorganisms & References \\
\hline R. officinalis & Urinary system infections & Eschechiria coli & Lagha, et al. [55] \\
\hline Scutellaria spp & Skin and soft tissue infections & Methicillin-resistant S. aureus & Chen, et al. [56] \\
\hline Curcumin & Oral infections & Porphyromonas gingivalis & Asteriou, et al. [57] \\
\hline $\begin{array}{l}\text { Acacia arabica } \\
\text { Tamarix aphylla L } \\
\text { Melia azedarach L }\end{array}$ & Oral infections & Main periodontopathogens & Khalid, et al. [58] \\
\hline Juglans regia L & Burns, trachea, urinary system & Pseudomonas aeruginosa & Dolatabati, et al. [59] \\
\hline $\begin{array}{l}\text { Citrus. sinensis, Laurus. nobilis, Elettaria } \\
\text { cardamomum, Allium cepa and } \\
\text { Coriandrum sativumexibiu }\end{array}$ & Systemic infections & Pseudomonas aeruginosa & $\begin{array}{l}\text { Al-Haidari, et al. } \\
{[60]}\end{array}$ \\
\hline Stryphnodendron adstringens & Vagina & Candida spp & Freitas, et al. [61] \\
\hline Ziziphora tenuior L. (Lamiaceae) & $\begin{array}{l}\text { Systemic infections, respiratory } \\
\text { system }\end{array}$ & Cryptococcus neoformans & Abu-Darwish, et al. [62] \\
\hline
\end{tabular}

drug found in turmeric and has been used against biofilms formed by this bacterium, changing the architecture of this bacterial community, destabilizing it. In addition, it has antibacterial activity in other periodontopathogens such as Fusobacterium nucleatum and Prevotella intermedia [57]. Other medicinal plants have been used in the treatment of oral infections, such as Acacia arabica, Tamarix aphylla L. and Melia azedarach $L$, with emphasis on $A$. arabica, which has shown promising results for antibiofile activity, reducing biofilm formation in the up to $73 \%$. surface pre-treated with the extract of this plant [58].

Pseudomonas aeruginosa is an opportunistic pathogen responsible for several serious infections, mainly in patients admitted to hospitals with some comormity. It is known for its ability to produce several virulence factors, such as biofilm. Dolatabati and colleagues [59], investigated samples from the trachea, urine and burns of hospitalized patients and identified $P$. aeruginosa in most of the collected samples and all of them forming biofilms. As a treatment, this author used the aqueous extract of the leaf of Juglans regia L. for the inhibition of planktonic growth and the methanol extract of the same plant for the inhibition of biofilm. The results of this study suggested that even strains resistant to biofilm-forming antibiotics can be inhibited by the methanol extract from the leaf of Juglans regia $\mathrm{L}$, which can be a promising strategy for the control and treatment of this bacterium in hospitals. Al-Haidari and collaborators (also described antibiofilm effects against $P$. aeruginosa, using extracts of CitrusSinensis, Laurus Nobilis, Elettaria cardamomum, Allium cepa and Coriandrum sativumexibiu, acting in the inhibition of quorum-sensing, a crucial mechanism for organization of the biofilm) [60].

Regarding clinical fungal infections, Freitas, et al. [61] described the action of the stem of Stryphnodendron adstringens in the treatment of vaginal candidiasis. Cryptococcus spp. they are also responsible for opportunistic infections, especially in immunocompromised patients. Abu-Darwish and colleagues [62] described the antibiofilm action of the essential oil extracted from Ziziphora tenuior L. (Lamiaceae), a medicinal plant from Jordan, on strains of Cryptococcus neoformans. With the treatment of this oil, the formation of the germ tube was inhibited and the amount of biofilm biomass was reduced [62].

\section{Conclusion}

Biofilm remains a problem not only in hospitals, but also in industries. This review describes the most promising anti-biofilm compounds, derived from natural products that act against bacteria and fungi. However, the treatment with these compounds must be studied in detail, since biofilms increase microbial resistance and have strategies to decrease the penetration of antimicrobial substances through their polysaccharide matrix. Therefore, more research is needed on anti-biofilm mechanisms and the search for new natural products that are less susceptible to the emergence of resistance.

\section{References}

1. Costa-Orlandi CB, Sardi JCO, Pitangui NS, et al. (2017) Fungal biofilms and polymicrobial diseases. J Fungi (Basel) 3: 22.

2. Lennox JE, Douthwright J, Delisle G, et al. (2020) Biofilms: Online manual. Disponível em.

3. Mitchell, Kaitlin F, Zarnowski Robert, Andes David R (2016) The extra cellular matrix offungal biofilms. Adv Exp Med Biol 931: 2135.

4. Singh S, Singh SK, Chowdhury I, et al. (2017) Understanding the mechanism of bacterial biofilms resistance to antimicro bialagents. Open Microbiol J 11: 53-62.

5. Mooney JA, Pridgen EM, Manasherob R, et al. (2018) Periprosthetic bacterial biofilm and quorum sensing. J Orthop Res 36: 2331-2339.

6. Alav I, Sutton JM, Rahman KM (2018) Role of bacterial efflux pumps in biofilm formation. J Antimicrob Chemother 73: 20032020.

7. Donlan RM, Costerton JW (2002) Biofilms: Survival mechanisms of clinically relevant microorganisms. Clin Microbiol Rev 15: 167193.

8. Jamal M, Ahmad W, Andleeb S, et al. (2018) Bacterial biofilm and associated infections. Journal of the Chinese Medical Association 81: 7-11. 
9. Hughes G, Webber MA (2017) Novel approaches to the treatment of bacterial biofilm infections. Br J Pharmacol 174: 2237 2246.

10. Albuquerque AC, Andrade C, Neves B (2014) Biocorrosão: Da integridade do biofilme à integridade do material. Corrosão e Protecção de Materiais 33: 18-23.

11. Hoveida L, Halaji M, Rostami S, et al. (2019) Biofilm-producing ability of Staphylococcus spp isolated from different foodstuff products. Ann Ig 31: 140-147.

12. Rossiter SE, Fletcher MH, Wuest WM (2017) Natural products as platforms to overcome antibiotic resistance. Chem Rev 117: $12415-12474$

13. Boukhatem MN, Boumaiza A, Nada HG, et al. (2020) Eucalyptus globulus essential oil as a natural food preservative: Antioxidant, antibacterial and antifungal properties in vitro and in a real food matrix (Orangina Fruit Juice). Applied Sciences 10: 5581.

14. Girish VM, Liang H, Aguilan JT, et al. (2019) Anti-biofilm activity of garlic extract loaded nanoparticles. Nanomedicine: Nanotechnology, Biologyand Medicine 20: 102009.

15. Jafri H, Ahmad I (2020) Thymus vulgarise ssential oil and thymo inhibit biofilms and interact synergistically with antifungal drugs against drug resistant strains of Candidaalbicans and Candidatropicalis. J Mycol Med 30: 100911.

16. Azman AS, Mawang Cl, Khairat JE et al. (2019) Actinobacteria - a promising natural sourceofanti-biofilmagents. International Microbiology 1-7.

17. Wijesundara NM, Rupasinghe HPV (2018) Essential oils from Origanum vulgare and Salvia officinalis exhibit antibacterial and anti-biofilm activities against Streptococcus pyogenes. Microb Pathog 117: 118-127.

18. Abachi S, Lee S, Rupasinghe HPV (2016) Molecular mechanisms of inhibition of Streptococcus species by phytochemicals. Molecules 21: 215 .

19. Sharma SM, Anderson M, Schoop SR, et al. (2010) Bactericidal and anti-inflammatory properties of a standardized echinacea extract (Echinaforce): Dual actions against respiratory bacteria. Phytomedicine 17: 563-568.

20. Zuo GY, Yang CX, Han J, et al. (2018) Synergism of prenylflavonoids from Morus alba root bark against clinical MRSA isolates. Phytomedicine 39: 93-99.

21. Zhou L, Ding Y, Chen Wet al. (2013) The in vitro study of ursolic acid and oleanolic acid inhibiting cariogenic microorganisms as well as biofilm. Oral dis 19: 494-500.

22. Kavanaugh NL, Ribbeck K (2012.) Selected antimicrobial essential oils eradicate Pseudomonas spp. And Staphylococcus aureus biofilms. Appl Environ Microbiol 78: 4057-4061.

23. Yong YY, Dykes GA, Choo WS (2019) Biofilm formation by Staphylococci in health-related environments and recent reports on their controlusing natural compounds. Crit Rev Microbiol 45: 201-222.

24. Husain FM, Ahmad I, Khan MS, et al. (2015) Sub-MICs of mentha piperita essential oil and menthol inhibits AHL mediated quorum sensing and biofilm of Gram-negative bacteria. Frontiers in microbiology 6: 420.

25. Brown KL, Hancock RE (2006) Cationic host defense (antimicrobial) peptides. Curr Opin Immunol 18: 24-30.

26. Hell E, Giske C, Nelson A, et al. (2010) Human cathelicidin peptide
LL37 inhibits both attachment capability and biofilm formation of Staphylococcus epidermidis. Lett Appl Microbiol 50: 211-215.

27. Dean SN, Bishop BM, van Hoek ML (2011) Natural and synthetic cathelicidin peptides with anti-microbial and antibiofilm activity against Staphylococcus aureus. BMC Microbiol 11: 114.

28. Gordya N, Yakovlev A, Kruglikova A, et al. (2017) Natural antimicrobial peptide complexes in the fighting of antibiotic resistant biofilms: Calliphoravicina medicinal maggots. Plos One 12: e0173559.

29. Martínez M, Polizzotto A, Flores N, et al. (2020) Antibacterial, anti-biofilmand in vivo activities of the antimicrobial peptides P5 and P6. 2. Microbial Pathogenesis 139: 103886.

30. Saleem HG, Aftab U, Sajid I, et al. (2015) Effect of crude extracts of selected actinomycetes on biofilm formation of A. schindleri, M. aci, and B. cereus. J Basic Microbiol 55: 645-651.

31. Nagoba BS, Selkar SP, Wadher BJ, et al. (2013) Aceticacid treatment of pseudomonal wound infections - a review. J Infect Public Health 6: 410-415.

32. Bjarnsholt $T$, Alhede $M$, Jensen $P \varnothing$, et al. (2015) Antibiofilm properties of acetic acid. Adv Wound Care 4: 363-372.

33. Grudzinski A, Agarwal A, Bhatnagar N, et al. (2015) Benefits and harms of citrate locking solutions for hemodialysis catheters: $A$ systematic review and meta-analysis. Can J Kidney Health Dis 2: 13.

34. Stanciuc AM, Gaspar A, Moldovan L, et al. (2011) In vitro antimicrobial activity of Romanian medicinal plants hydroalcoholic extracts on planktonic and adhered cells. Roum Arch Microbiol Immunol 70: 11-14.

35. Choi HA, Cheong DE, Lim HD, et al. (2017) Antimicrobial and anti-biofilm activities of the methanol extracts of medicinal plantsagainst dental pathogens Streptococcus mutans and Candidaalbicans. J Microbiol Biotechnol 27: 1242-1248.

36. Freitas MA, Andrade JC, Alves AIS, et al. (2020) Use ofthe natural products from the leaves of the fruit full tree Persea americana against Candida sp. Biofilms using acrylicresin discs. Sci Total Environ 703: 134779 .

37. Girardot M, Imbert C (2016) Natural sources as innovative solutions against fungal biofilms. Adv Exp Med Biol 931: 105-125.

38. Silva AR, Neto JBA, Silva CR, et al. (2016) Berberine antifungal activity in fluconazole-resistant pathogenic yeasts: Action mechanism evaluated by flow cytometry and biofilm growth inhibition in Candida spp. Antimicrob Agents and chemother 60: 35513557.

39. Almeida-Apolonio AA, Cupozak-Pinheiro WJ, Berres VM, et al. (2018) Control of cryptococcus gattii biofilms by an ethanolic extract of cochlospermum regium (schrank) pilger leaves. The Scientific World Journal 2018: 5764187.

40. Brochot A, Guilbot A, Haddioui L, et al. (2017) Antibacterial, antifungal, and antiviral effects of three essential oil blends. Microbiologyopen 6: e00459.

41. Banu SF, Rubini D, Shanmugavelan P, et al. (2018) Effects of patchouli and cinnamon essential oils on biofilm and hyphae formation by Candida species. J Mycol Med: 28: 332-339.

42. Rajkowska K, Nowicka KP, Kunicka SA (2019) Effect of clove and thyme essential oils on candida biofilm formation and the oil distribution in yeast cells. Molecules 24: 1954.

43. Almeida CA, Azevedo M, Chaves F, et al. (2018) Piper essen- 
tial oils inhibit Rhizopusoryzaeg rowth, biofilm formation, and rhizopuspepsin activity. Can J Infect Dis Med Microbiol 2018: 5295619.

44. Oshiro KG, Rodrigues G, Monges BED, et al. (2019) Bioactive peptides against fungal biofilms. Frontiers in microbiology 10: 2169.

45. Tebbets B, Yu Z, Stewart D, et al. (2013) Identification of antifungal natural products via Saccharomyces cerevisiae bioassay: Insights intomacrotetrolide drug spectrum, potencyandmode of action. Sabouraudia 51: 280-289.

46. Ceresa C, Rinaldi M, Chiono V, et al. (2016) Lipopeptidesfrom bacillus subtilis AC7 inhibit adhesion and biofilm formation of Candidaalbicans on silicone. Antonie Van Leeuwenhoek 109: 1375-1388.

47. Paraszkiewicz K, Moryl M, Płaza G, et al. (2019) Surfactants of microbial origin as antibiofilm agents. International Journal of Environmental Health Research 1-20.

48. Høiby N, Bjarnsholt T, Moser C, et al. (2015) ESCMID guideline for the diagnosis and treatment of biofilm infections 2014. Clin Microbiol Infect 1-25.

49. Bhatta DR, Hamal D, Shrestha R, et al. (2018) Bacterial contamination of frequently touched objects in a tertiary care hospital of Pokhara, Nepal: How safe are ourhands? Antimicrob Resist Infect Control 7: 97.

50. Chowdhury D, Tahir S, Legge M, et al. (2018) Transferofdry surface biofilm in the healthcare environment: The role of healthcare workers' hands as vehicles. J Hosp Infect 100: e85-e90.

51. Menoita E, Santos V, Testas C, et al. (2012) Biofilms: Knowing the entity. Journal of Aging and Innovation 1: 23-32.

52. Tsai MH, Chu SM, Hsu JF, et al. (2015) Breakthrough bacteremia in the neonatal intensivecareunit: Incidence, riskfactors, and attributable mortality. Am J Infect Control 43: 20-25.

53. Uppuluri Priya, Lopez-Ribot JL (2016) Go forthand colonize: Dispersal from clinically important microbial biofilms. PloS pathogens 12: e1005397.
54. Fong J, Zhang C, Yang R, et al. (2018) Combination therapy strategy of quorum quenching enzyme and quorum sensing inhibitor in suppressing multiple quorum sensing pathways of $P$. aeruginosa. Scientific reports 8: 1155.

55. Lagha Rihab, Fethi Ben Abdallah, Badriah Osama Al-Sarhan, et al. (2019) Antibacterial and biofilm inhibitory activity of medicinal plant essential oils against escherichia coli isolatedfrom UTI patients. Molecules 24: 1161.

56. Chen SW, Liu F, Zhu K, et al. (2019) Natural products that target virulence factors in antibiotic-resistant staphylococcus aureus. J Agric Food Chem 67: 13195-13211.

57. Asteriou E, Gkoutzourelas A, Mavropoulos A, et al. (2018) Curcumin for the management of periodontitis and early ACPA-positive rheumatoid arthritis: Killing two birds with one stone. Nutrients 10: 908.

58. Khalid M, Hassani D, Bilal M, et al. (2017) Identification of oral cavity biofilm forming bacteria and determination of their growth inhibition by Acacia arabica, Tamarixaphylla L. and Meliaazedarach L. medicinal plants. Arch Oral Biol 81: 175-185.

59. Dolatabadi Samaneh, Moghadam Hediyeh Nesari, Mahdavi-Ourtakand, et al. (2018) Evaluating the anti-biofilm and antibacterial effects of Juglans regia L. extracts against clinical isolates of Pseudomonas aeruginosa. Microb Pathog 118: 285-289.

60. Al-Haidari RA, Shaaban MI, Ibrahim SR, et al. (2016) Anti-quorum sensing activity of some medicinal plants. Afr J Tradit Complement Altern Med 13: 67-71.

61. Freitas ALD, Vanessa Kaplum, Diego Conrado Pereira Rossi, et al. (2018) Proanthocyanidi polymeric tannins from Stryphnodendron adstringens are effective against Candida spp. Isolates and for vaginal candidiasis treatment. J Ethnopharmacol 216: 184190.

62. Abu-Darwish, C Cabral, M J Gonçalves, et al. (2016) Ziziphora tenuior L. essential oil from dana biosphere reserve (Southern Jordan); Chemical characterization and assessment of biological activities. J Ethnopharmacol 194: 963-970. 